\title{
Within-day traffic assignment and signal setting in road evacuation: a procedure with explicit path enumeration
}

\author{
F. A. Marcianò, G. Musolino \& A. Vitetta \\ Università degli Studi Mediterranea di Reggio Calabria, \\ DIMET- Dipartimento di Informatica, Matematica, \\ Elettronica e Trasporti, Italy
}

\begin{abstract}
In the sphere of the SICURO research project, we propose a framework for signal setting design of road intersections with explicit path enumeration. The framework has two main components: an optimization procedure for signal setting design and a within-day simulation procedure to capture effects of signal setting modification on path choice behaviour. The paper describes the elements of the simulation procedure and illustrates some disaggregate results obtained from its application on an experimental test site.

Keywords: within-day traffic assignment, signal setting design, evacuation.
\end{abstract}

\section{Introduction}

Signalized intersections are critical points of a transport network. Signal setting design is an effective strategy to increase network capacity and to mitigate congestion in urban areas and with particular reference to emergency conditions. However, signal setting design models in literature do not provide solutions that take into account path choice behaviour and there are few examples of development and application of signal setting design models in evacuation conditions.

We represent the problem of signal setting design of intersections in a road network as an optimization problem subject to equilibrium constraints. In other words, travel demand flows must be consistent with travel times generated by signal setting parameters. 
Our work is part of the SICURO research project, carried out by the Laboratory for Transport Systems Analysis of the Università degli Studi Mediterranea di Reggio Calabria (Italy). The general objective is risk reduction in urban areas in terms of exposure [1]. Specific research lines concern travel demand models [2-4], planning processes and guidelines [5-7], route design for emergency vehicles [8-10], transport supply and travel demand-supply interaction [11].

In the sphere of the last research line, we developed a framework for signal setting design of road intersections with endogenous estimation of path flows [12]. The framework has two main components: (i) an optimization procedure for signal setting design [13]; (ii) a within-day simulation procedure to capture effects of signal setting modification on path choice behaviour presented in this paper. The paper is structured into four sections. Section 2 briefly recalls the proposed framework. Section 3 focuses on the elements of the simulation procedure. Section 4 illustrates some disaggregate results provided by the simulation procedure applied on an experimental test site. The last section reports the final remarks.

\section{Framework}

The proposed framework for signal setting parameters design generates potential solutions and simulates their effects in order to optimize an objective function. The framework contains two main interacting procedures:

- a solution generation procedure generates a current vector of signal setting parameters, $\mathbf{y}$,

- a solution simulation procedure estimates path flows and costs at equilibrium consistently with vector, $\mathbf{y}$.

The procedures and their interactions are schematically presented in figure 1 in terms of inputs, parameters and outputs.

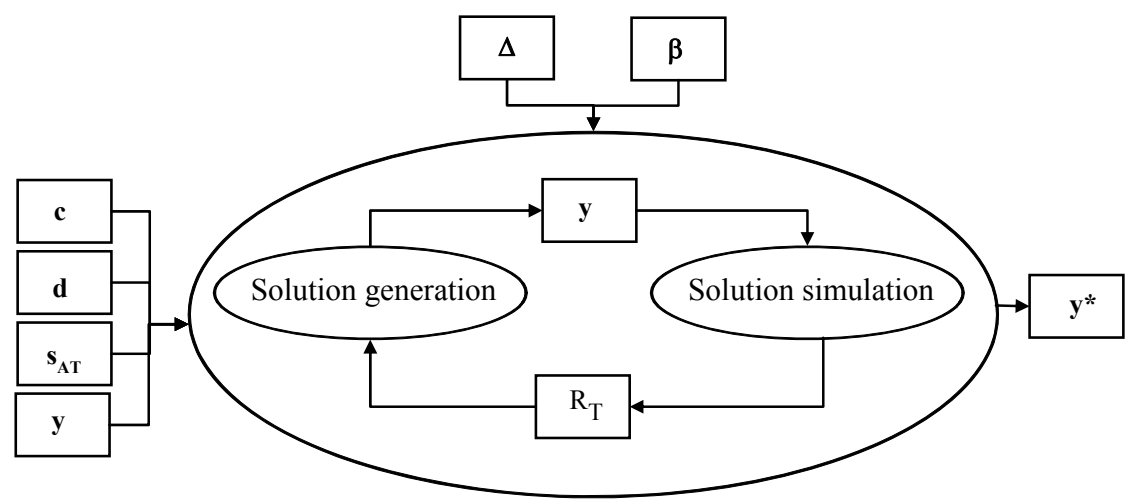

Figure 1: Inputs, parameters and outputs of the framework. 
Inputs are related to the transport system: d, vector of demand flows; c, vector of link costs on non-congested network; s, vector of saturation flows on each access; $\mathbf{y}$, vector of initial signal setting parameters (updated with optimization). Parameters are $\Delta$, matrix of network topology and $\beta$, vector of transport models parameters. Output is the vector of solutions at equilibrium, $\mathbf{y}^{*}$, that optimizes the objective function (optimal value of $\mathbf{y}$ ).

Transport system performance, for each vector $\mathbf{y}$, is synthesized in a global network indicator, $\mathrm{R}$, which represents the objective function to be optimized. Therefore, the solutions are compared and evaluated in terms of the values of the objective function. The following section analytically describes the solution simulation procedure, while a description of the solution generation procedure can be found in $[12,13]$.

\section{Solution simulation procedure}

The solution simulation procedure has a bi-level structure: the first level, named static simulation, provides link flows and congested costs at equilibrium and generates the first k-paths; the second level, named dynamic simulation, estimates vehicular flow propagation and hence the delay on the network.

\subsection{Static simulation}

The static simulation is executed by means of a sequential application of the following algorithms (Figure 2). The first is a mean successive average algorithm with implicit path enumeration (MSA-I), which provides the vectors of congested link costs, $\mathbf{c}^{*}$, and of link flows, $\mathbf{f}^{*}$, at equilibrium. Costs of vector, $\mathbf{c}$ (which are link travel times obtained as the sum of running and waiting components), are updated through congested cost functions, $\mathbf{c}=\boldsymbol{c}(\mathbf{f}, \mathbf{y})$, dependent on vector $\mathbf{y}$.

The model implemented in the MSA-I algorithm is a Stochastic User Equilibrium (SUE) model (formulated in terms of link flows vector at equilibrium, $\mathbf{f}^{*}$ ):

$$
\mathbf{f}^{*}=f_{S N L}\left(c\left(\mathbf{f}^{*}, \mathbf{y}\right) ; \mathbf{d}\right)=\Delta P\left(c\left(\mathbf{f}^{*}, \mathbf{y}\right)\right) \mathbf{d} \quad \mathbf{f}^{*} \in \mathrm{S}_{\mathrm{f}}
$$

with

$f_{S N L}(\cdot)$, vector of stochastic network loading functions;

$c(\cdot)$, vector of link cost functions;

$\boldsymbol{P}(\cdot)$, matrix of path choice probability functions;

$\mathrm{S}_{\mathrm{f}}$, feasibility set of link flows.

The second is a k-paths algorithm which generates the first k-paths of minimum congested costs on every origin-destination pair [14-16]. Paths are generated in two steps:

- definition of path choice set with a selective approach, which considers a path admissible if it satisfies a defined criterion;

- generation of k-paths through the evaluation of utilities estimated with an attribute (time, distance, etc.) associated to the above criterion. 


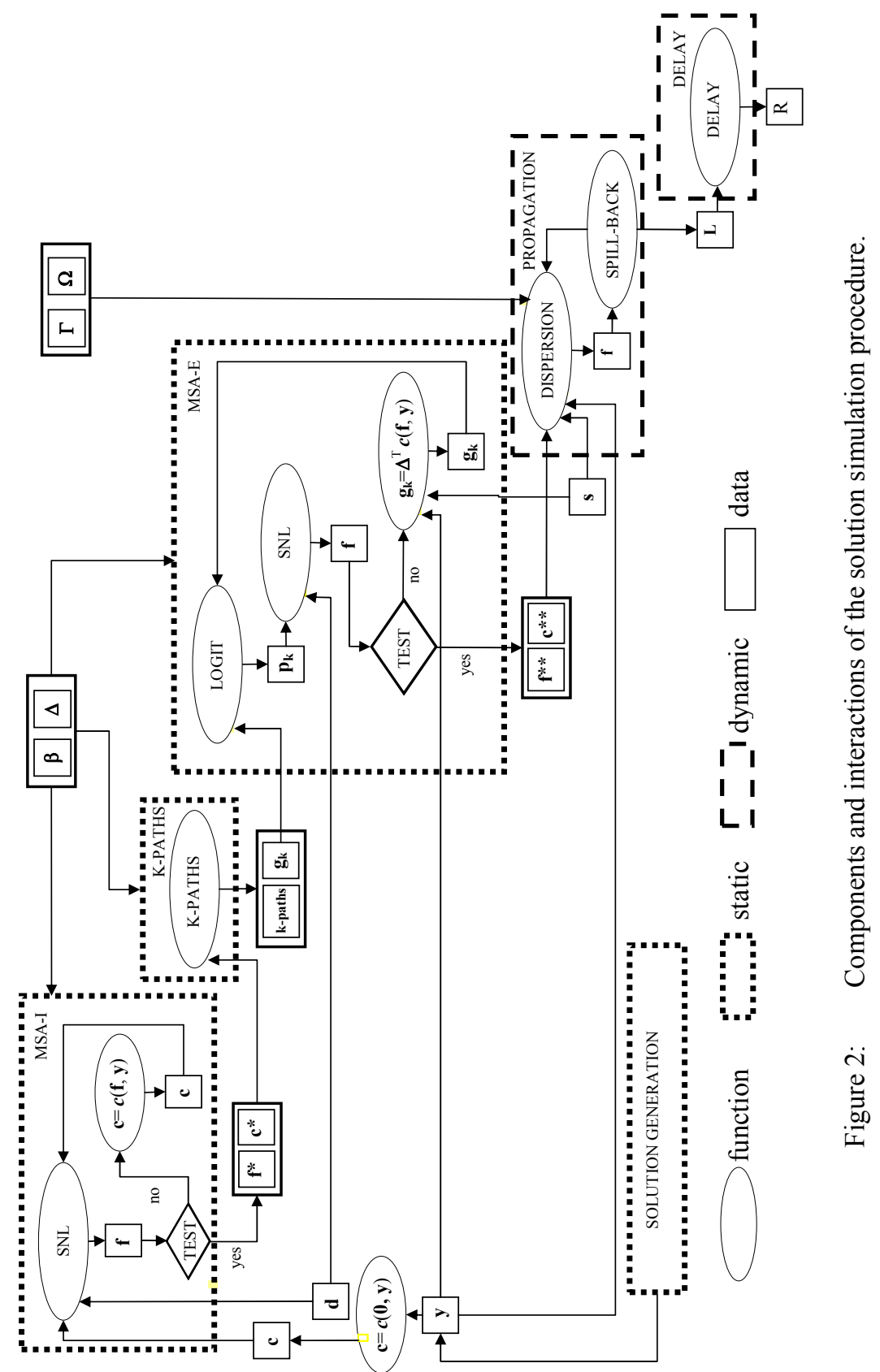


The third is a mean successive average algorithm with explicit enumeration of the first k-paths of minimum congested costs (MSA-E), which provides the vectors of congested link costs, $\mathbf{c}^{* *}$, and link flows, $\mathbf{f}^{* *}$, and consequently kpaths flows, $\mathbf{h}_{\mathbf{k}}{ }^{* *}$, at equilibrium.

The vector of k-path choice probabilities, $\mathbf{p}_{\mathbf{k}}$, is updated through a logit path choice model:

where

$$
\mathrm{p}_{\mathrm{od}, \mathrm{r}}=\exp \left(\mathrm{V}_{\mathrm{od}, \mathrm{r}}\right) / \Sigma_{\mathrm{u} \in \mathrm{I}_{\mathrm{od}, \mathrm{k}}} \exp \left(\mathrm{V}_{\mathrm{od}, \mathrm{u}}\right) \quad \forall \text { od }
$$

$\mathrm{p}_{\text {od, }, \mathrm{r}}$, choice probability of path $\mathrm{r}$ connecting origin-destination pair od;

$V_{o d, r}=\beta g_{r}$, systematic utility of path $r$ connecting origin-destination pair od;

$\mathrm{I}_{\mathrm{od}, \mathrm{k}}$, path choice set composed of first k-path of minimum costs connecting origin-destination pair od;

$\beta$, choice parameter.

The model implemented in the MSA-E algorithm is that of eqn. (1).

\subsection{Dynamic simulation}

The dynamic simulation is developed by means of a sequence of algorithms which allow the propagation of vehicular flow on links to be estimated, taking into account spill-back effects and the global delay of vehicles on the network. The dispersion algorithm is derived from Robertson [17], with the difference that in the proposed procedure vehicular flows on individual paths are simulated according to a behavioural approach. Robertson assumes exogenous turning percentages (or exogenous paths between origin-destination pairs); vehicular flow profiles are thus cyclic in the sense that they do not change with the modification of signal setting configuration. In our algorithm the results are not affected by the sequence of visited nodes and vehicular flow profiles may be acyclic due to the modification of flows on individual paths.

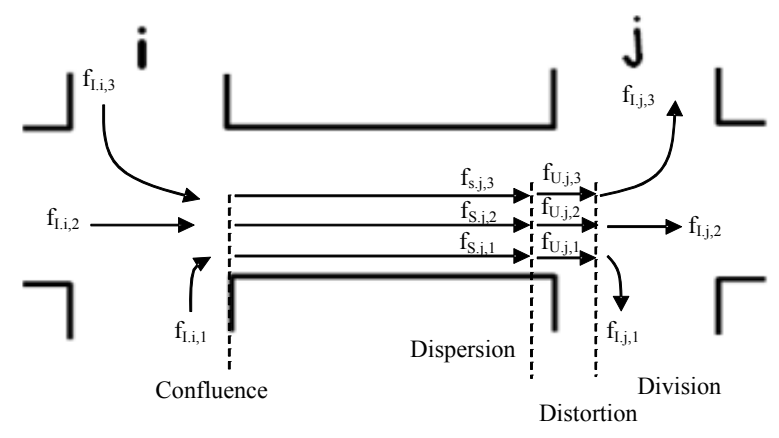

Figure 3: Dispersion algorithm: case of link ij belonging to three paths.

The algorithm requires as exogenous input the stage matrix, $\Gamma$, and the access-path matrix, $\Omega$, and provides as output the aggregate phenomena of confluence, dispersion, distortion and division [18]. Turning percentages are 
obtained from the path flows. An example for a link from node $\mathrm{i}$ to node $\mathrm{j}$ with 3 inputs and 3 outputs turns is reported in Figure 3. The model reported below is in a general case where index $r$ is extended to all turns.

The confluence model estimates vehicular flow at node $i$ at instant $t, f_{I . i}(t)$ :

$$
\mathrm{f}_{\mathrm{I} . \mathrm{i}}(\mathrm{t})=\Sigma_{\mathrm{r}} \mathrm{f}_{\mathrm{I} . \mathrm{i}, \mathrm{r}}(\mathrm{t})
$$

with $\mathrm{f}_{\mathrm{I}, \mathrm{i}, \mathrm{r}}(\mathrm{t})$, vehicular flow at node $\mathrm{i}$ related to path $\mathrm{r}$ at instant $\mathrm{t}$ (it is exogenous if $\mathrm{i}$ is a source).

The dispersion model estimates vehicular flow at node $\mathrm{j}$ at instant $\mathrm{t}+\Delta \mathrm{t}$, $\mathrm{f}_{\mathrm{S} . \mathrm{j}}(\mathrm{t}+\Delta \mathrm{t})$ :

$$
\mathrm{f}_{\mathrm{S} . \mathrm{j}}(\mathrm{t}+\Delta \mathrm{t})=\Sigma_{\mathrm{r}} \mathrm{f}_{\mathrm{S} . \mathrm{j}, \mathrm{r}}(\mathrm{t}+\Delta \mathrm{t})
$$

with $\mathrm{f}_{\mathrm{S} . \mathrm{j}, \mathrm{r}}(\mathrm{t}+\Delta \mathrm{t})$, vehicular flow at node $\mathrm{j}$ of path $\mathrm{r}$ at instant $\mathrm{t}+\Delta \mathrm{t}$

$$
\mathrm{f}_{\mathrm{S} . \mathrm{j}, \mathrm{r}}(\mathrm{t}+\Delta \mathrm{t})=\mathrm{F} \mathrm{f}_{\mathrm{I} . \mathrm{i}, \mathrm{r}}(\mathrm{t})+(1-\mathrm{F}) \mathrm{f}_{\mathrm{S} . \mathrm{j}, \mathrm{r}}(\mathrm{t}+\Delta \mathrm{t}-1)
$$

where

$\Delta \mathrm{t}=\operatorname{int}\left(0.5+0.8 \mathrm{t}_{\mathrm{ij}} / \tau\right)$;

$\mathrm{F}=1 /\left(1+0.4 \mathrm{c}_{\mathrm{ij}}\right)$;

$\mathrm{c}_{\mathrm{ij}}$, running time on link $\mathrm{ij}$, derived from MSA-E;

$\tau$, simulation step (equal to 1 second).

The distortion model estimates vehicular flow exiting from node $\mathrm{j}, \mathrm{f}_{\mathrm{U} . \mathrm{j}}$ :

$\mathrm{f}_{\mathrm{U} . \mathrm{j}}(\mathrm{t})=\Sigma_{\mathrm{r}} \mathrm{f}_{\mathrm{U} . \mathrm{j}, \mathrm{r}}$

with

$\mathrm{f}_{\mathrm{U} . \mathrm{j}, \mathrm{r}}(\mathrm{t})= \begin{cases}0 & \text { if red } \\ \min \left(\mathrm{s}_{. \mathrm{j}, \mathrm{a}, \mathrm{r}} ;\left(\mathrm{L}_{\mathrm{a}, \mathrm{j}, \mathrm{r}}(\mathrm{t}) / \tau\right)+\mathrm{f}_{\mathrm{S} . \mathrm{j}, \mathrm{r}}(\mathrm{t})\right) & \text { if green }\end{cases}$

where

$s_{\text {.j,a,r }}(t)$, saturation flow of access a of node $j$ belonging to path $r$ at instant $t$;

$\xi_{\mathrm{r}}=\mathrm{h}_{\mathrm{r}} / \mathrm{h}_{\mathrm{a}}$, saturation flow percentage of access a of node $\mathrm{j}, \mathrm{s}_{\mathrm{a}, \mathrm{j}}$, belonging to path

$\mathrm{r}$;

$\mathrm{h}_{\mathrm{r}}$, flow on path $\mathrm{r}$;

$\mathrm{h}_{\mathrm{a}}$, flow on access $\mathrm{a}$;

$\mathrm{L}_{\mathrm{a}, \mathrm{j}, \mathrm{r}}(\mathrm{t})$, queue length on access a of node $\mathrm{j}$ related to vehicles belonging to path $\mathrm{r}$ at instant $\mathrm{t}$.

The division model estimates how vehicular flow exiting from node $\mathrm{j}, \mathrm{q}_{\mathrm{U} . \mathrm{j}}$, is distributed along links with node $\mathrm{j}$ as the origin node.

The spill-back algorithm simulates spill-back phenomenon, which is present when queue length exceeds link length, blocking vehicular flow on downstream links. It activates a fictitious red phase on the accesses where vehicular manoeuvres are blocked. The duration of fictitious red is equal to the time required for queue dissipation, termed spill-back time, $t_{\mathrm{SB}}$, which influences the dispersion model. 
The steps of the spill-back algorithm are the following:

1. calculation of queue length [veh] on each link as the sum of queue lengths on each link access;

2. multiplication by average vehicle occupation (e.g. $5 \mathrm{~m}$ ) and division by the number of link lanes, obtaining the queue length [m];

3. comparison between average queue length and link length:

3.1. if the queue length is greater than the link length, spill-back is present;

3.2. otherwise, there is no spill-back;

4. if spill-back is present (condition 3.1)

4.1. division of queue spill-back by the average vehicle occupation to obtain the value expressed in vehicles;

4.2. calculation of $t_{\mathrm{SB}}$, as a ratio between queue spill-back and total saturation, $\mathrm{s}_{\mathrm{TOT}}$, of accesses where manoeuvres are blocked;

4.3. introduction of fictitious red for $\mathrm{t}_{\mathrm{SB}}$ on accesses involved with spillback and setting saturation flow equal to zero.

Sequential application of the above two algorithms allows the estimation of the average queue length on a link ij at instant $t, \mathrm{~L}_{\mathrm{ij}}(\mathrm{t})$, as:

$$
\mathrm{L}_{\mathrm{ij}}(\mathrm{t})=\sum_{. t \in 1 \ldots \mathrm{T} / \tau}\left(\mathrm{q}_{\mathrm{S} . \mathrm{j}}(\mathrm{t})-\mathrm{q}_{\mathrm{U} . \mathrm{j}}(\mathrm{t})\right) \tau
$$

where

$\mathrm{q}_{\mathrm{S} . \mathrm{j}}(\mathrm{t})$ are vehicular flows estimated through dispersion model (eqn. 4);

$\mathrm{q}_{\mathrm{U} . \mathrm{j}}(\mathrm{t})$, vehicular flows estimated through a distortion model (eqn. 6);

$\mathrm{T}$, time interval defined as a multiple of a cycle duration (assuming that there is no queue at initial instant of $\mathrm{T}$ );

$\mathrm{T} / \tau$, number of sub-intervals of amplitude $\tau$.

The delay algorithm allows calculation of the global delay of vehicles on the network, R, according to the deterministic queue theory, from vehicular flows simulated through the previous algorithms:

$$
\mathrm{R}=\Sigma_{\mathrm{t} \in 1 \ldots \mathrm{T} / \tau} \Sigma_{(\mathrm{ij})} \mathrm{L}_{\mathrm{ij}}(\mathrm{t}) \tau=\Sigma_{\mathrm{t} \in 1 \ldots \mathrm{T} / \tau} \Sigma_{(\mathrm{ij})}\left(\mathrm{q}_{\mathrm{S} . \mathrm{j}}(\mathrm{t})-\mathrm{q}_{\mathrm{U} . \mathrm{j}}(\mathrm{t})\right) \tau^{2}
$$

\section{Application}

An application was executed on the experimental evacuation test site defined in the SICURO project. The objective was to illustrate some disaggregate results provided by the simulation procedure.

The test required the previous build-up of travel demand [19, 20], network and within-day traffic assignment models [21, 22], and the monitoring of the planning process $[23,24]$. A coordinated set of traffic signals was then introduced to regulate vehicle access to the evacuation area (figure 4). The solution generation procedure provided the optimal configuration of signal setting parameters, $\mathbf{y}^{*}$, and thus the solution simulation procedure estimated the effects on path choice behaviour and on propagation of vehicular flows.

Aggregate results concerning the whole framework were presented and discussed by means of the indicators presented in [13]. Disaggregate results 
concern time profiles of vehicular flows estimated through the algorithms of the solution simulation procedure. We focused on profiles estimated through the confluence $\left(f_{I . i}\right)$, dispersion $\left(f_{S . j}\right)$ and distortion $\left(f_{U . j}\right)$ models of the propagation algorithm. Figures 5 and 6 depict the three profiles respectively for links 11-12 and 13-12 (figure 4). It emerges that, in general, the shapes of vehicular flow profiles differ along the simulated period $(300 \mathrm{sec})$ due to the modification of flows on individual paths. The saturation flows are respectively 3180 [veh/h] for link 11-12 and $1590[\mathrm{veh} / \mathrm{h}]$ for link 13-12; in the second case profiles are bounded.

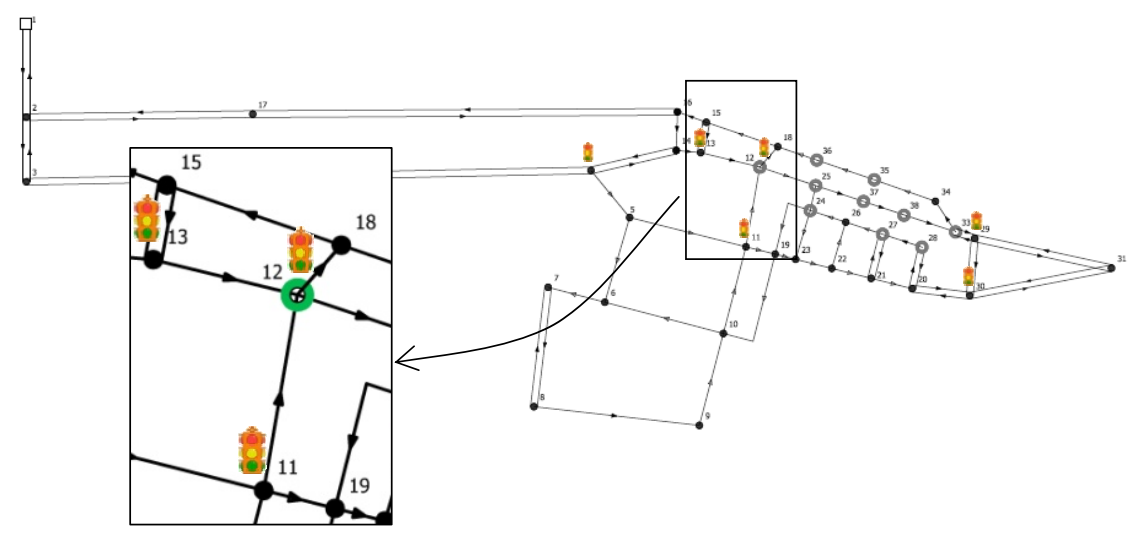

Figure 4: $\quad$ Graph, location of traffic signals and intersection 12.

Figure 7 shows the delays of vehicles crossing signalized intersection $12, \mathrm{R}_{12}$, plotted against different values of offsets, $\phi_{12}$. The zero value corresponds to the value of absolute offset obtained from the optimization model. The picture shows that the minimum delay corresponds to the above zero value, confirming that it ensures the maximum performance for the examined intersection.

\section{Final remarks}

The paper dealt with the problem of signal setting design of intersections in a road network as an optimization problem subject to equilibrium constraints, where travel demand flows must be consistent with travel times generated by signal setting parameters. According to this requirement, we developed a framework for signal setting design of road intersections with endogenous estimation of path flows. The framework has two main components: an optimization procedure for signal setting design and a within-day simulation procedure to capture the effects of signal setting modification on path choice behaviour presented in this paper.

The paper described the elements of the simulation procedure and illustrated some disaggregate results obtained from its application on an experimental test site. The simulations showed that, in general, vehicular flow profiles differ 
during the simulated period, due to the modification of vehicular flows on individual paths.

Further research will aim to develop the system of models in order to create an integrated design of signal setting and network topology parameters and model validation through the definition of integrated design scenarios on a real test site in evacuation conditions.
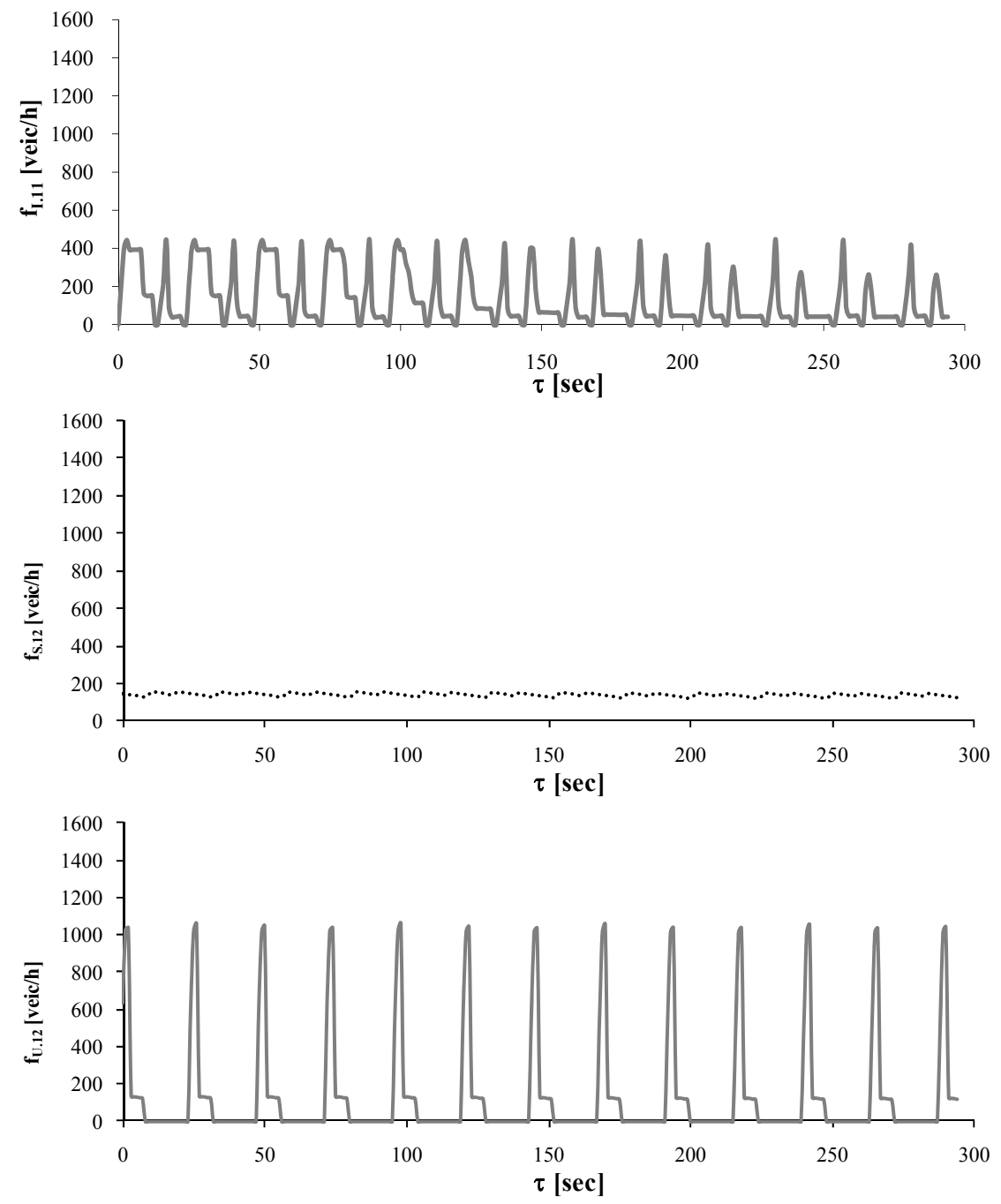

Figure 5: Confluence $\left(f_{\mathrm{I} .11}\right)$, dispersion $\left(f_{\mathrm{S} .12}\right)$ and distortion $\left(f_{\mathrm{U} .12}\right)$ vehicular flows on link 11-12 (see figure 4). 

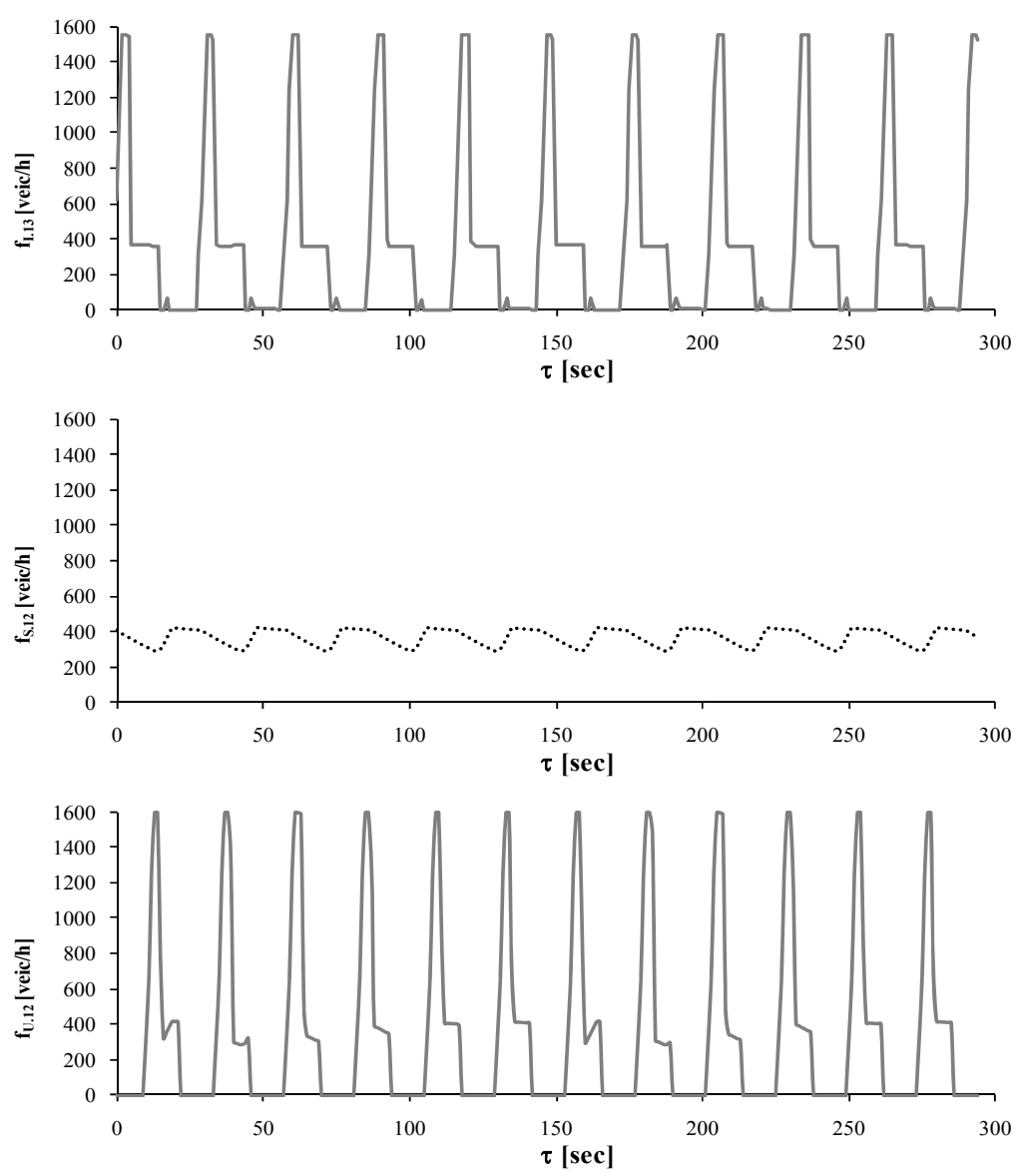

Figure 6: Confluence $\left(f_{\mathrm{I} .13}\right)$, dispersion $\left(f_{\mathrm{S} .12}\right)$ and distortion $\left(\mathrm{f}_{\mathrm{U} .12}\right)$ vehicular flows on link 13-12 (see figure 4).

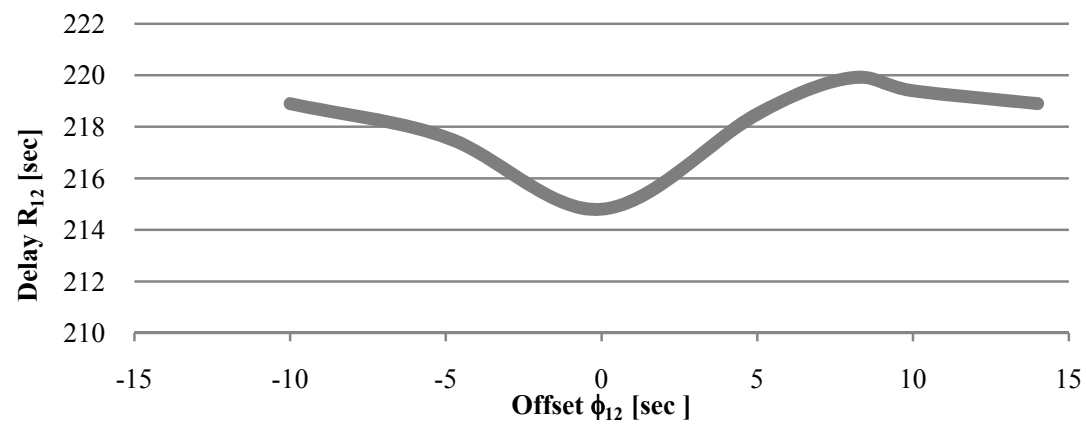

Figure 7: Delays $\left(\mathrm{R}_{12}\right)$ versus offsets $\left(\phi_{12}\right)$ at node 12 (see figure 4$)$. 


\section{References}

[1] Russo F. \& Vitetta A., Risk evaluation in a transportation system. International Journal of Sustainable Development and Planning, 1 (2), pp. 170-191, 2006.

[2] Russo F. \& Chilà G., Safety of users in road evacuation: Modelling and DSS for demand. Proc. of Sustainable Development and Planning IV, vol.1, Brebbia C.A. (ed.), WIT Press, Southampton, pp. 465-474, 2009.

[3] Russo F. \& Chilà G., Dynamic approaches to demand model in evacuation conditions. Proc. of Urban Transport XVI, Urban Transport and the Environment in the 21st century, Brebbia C.A. (ed.), WIT Press, Southampton, pp. 303-312, 2010.

[4] Russo F. \& Chilà G., A sequential dynamic choice model to simulate demand in evacuation conditions. Proc. of Risk analysis VII \& Brownfields $V$, Brebbia C.A. (ed.), WIT Press, Southampton, pp. 431-442, 2010.

[5] Russo F. \& Rindone C., Safety of users in road evacuation: Modelling and DSS for LFA in the planning process. Proc. of Sustainable Development and Planning IV, vol.1, Brebbia C.A. (ed.), WIT Press, Southampton, pp. 453-464, 2009.

[6] Russo F. \& Rindone C., Evaluation methods for evacuation planning. Proc. of Urban Transport XVI, Urban Transport and the Environment in the 21st century, Brebbia C.A. (ed.), WIT Press, Southampton, pp. 335-343, 2010.

[7] Russo, F. \& Rindone C., Data Envelopment Analysis (DEA) for evacuation planning. Proc. of Risk Analysis VII \& Brownfields V, Brebbia C.A. (ed.), WIT Press, Southampton, pp. 455-467, 2010.

[8] Vitetta A., Quattrone A. \& Polimeni A., Safety of users in road evacuation: design of path choice models for emergency vehicles. Proc. of Urban Transport XIII, Urban Transport and the Environment in the 21st century, Brebbia C.A. (ed.), WIT Press, Southampton, pp. 803-812, 2007.

[9] Vitetta A., Quattrone A. \& Polimeni A., Safety of users in road evacuation: algorithms for path design of emergency vehicles, Proc. of Urban Transport XIV, Urban Transport and the Environment in the 21st century, Brebbia C.A. (ed.), WIT Press, Southampton, pp. 727-737, 2008.

[10] Vitetta A., Quattrone A. \& Polimeni A., Safety of users in road evacuation: Modelling and DSS for paths design of emergency vehicles. Proc. of Sustainable Development and Planning IV, vol.1, Brebbia C.A. (ed.), WIT Press, Southampton, pp. 485-495, 2009.

[11] Vitetta A., Musolino G. \& Marcianò F.A., Safety of users in road evacuation: Modelling and DSS for transport supply and supply-demand interaction. Proc. of Sustainable Development and Planning IV, vol.1, Brebbia C.A. (ed.), WIT Press, Southampton, pp. 475-484, 2009.

[12] Marcianò F.A., Musolino G. \&Vitetta A., A system of models for signal setting design of a signalized road network in evacuation conditions. Proc. of Urban Transport XVI, Urban Transport and the Environment in the 21st century, Brebbia C.A. (ed.), WIT Press, Southampton, pp. 313-323, 2010. 
[13] Marcianò F.A., Musolino G. \& Vitetta A., Signal setting design on a road network: application of a system of models in evacuation conditions. Proc. of Risk Analysis VII \& Brownfields V, Brebbia C.A. (ed.), WIT Press, Southampton, pp. 443-454, 2010.

[14] Russo, F. \& A. Vitetta. An assignment model with modified Logit, which obviates enumeration and overlapping problems, Transportation, 30, pp. 177-201, 2003.

[15] Russo F. \& Vitetta A., La ricerca di percorsi in una rete di trasporto: algoritmi di minimo costo ed estensioni. FrancoAngeli, Milan, 2006.

[16] Russo F. \& Vitetta A., Reverse assignment: calibrating link cost functions and updating demand from traffic counts and time measurements. Inverse Problems in Science \& Engineering, ISSN 1741-5977 print/ISSN 1741-5985 Taylor \& Francis DOI: 10.1080/17415977.2011.565339. Forthcoming.

[17] Robertson D.I., 'TRANSYT' method for area traffic control. Traffic Engineering and Control, 10, pp. 276-81, 1969.

[18] Marcianò F.A., Una metodologia per il progetto dei parametri di regolazione di una rete di intersezioni stradali semaforizzate: sperimentazione in condizioni di emergenza, $\mathrm{PhD}$ thesis, Università degli Studi Mediterranea di Reggio Calabria, 2010.

[19] Russo F. \& Chilà G., Safety of users in road evacuation: demand models. Proc. of Urban Transport XIII, Urban Transport and the Environment in the 21st century, Brebbia C.A. (ed.), WIT Press, Southampton, pp. 773-782, 2007.

[20] Russo F. \& Chilà G., Safety of users in road evacuation: RP vs. SP surveys in demand analysis. Proc. of Urban Transport XIV, Urban Transport and the Environment in the 21st century, Brebbia C.A. (ed.), WIT Press, Southampton, pp. 703-713, 2008.

[21] Vitetta A., Musolino G. \& Marcianò F.A., Safety of users in road evacuation: Supply and demand-supply interaction models for users. Proc. of Urban Transport XIII, Urban Transport and the Environment in the 21st century, Brebbia C.A. (ed.), WIT Press, Southampton, pp.783-792, 2007.

[22] Vitetta A., Musolino G. \& Marcianò F. A., Safety of users in road evacuation: calibration of cost functions and simulation. Proc. of Urban Transport XIV, Urban Transport and the Environment in the 21st century, Brebbia C.A. (ed.), WIT Press, Southampton, pp. 715-725, 2008.

[23] Russo F. \& Rindone C., Safety of users in road evacuation: planning internal processes and guidelines. Proc. of Urban Transport XIII, Urban Transport and the Environment in the 21st century, Brebbia C.A. (ed.), WIT Press, Southampton, pp. 825-834, 2007.

[24] Russo F. \& Rindone C., Safety of users in road evacuation: the logical framework approach in evacuation planning. Proc. of Urban Transport $X I V$, Urban Transport and the Environment in the 21st century, Brebbia C.A. (ed.), WIT Press, Southampton, pp. 751-760, 2008. 